\title{
SCIENCE
}

Friday, March 12, 1915

CONTENTS

The American Association for the Advancement of Science:-

The Function and Test of Definition and Method in Psychology: PrOFESSOR W. B. Pillsbury $\ldots \ldots \ldots \ldots \ldots \ldots \ldots \ldots \ldots \ldots . \ldots 1$

Mrs. Henry Draper: Annie J. CannoN . . . 380

A New Glacial Park: Dr. JoHN M. Clarke. 382

The United States Geological Surven at the Panama Exposition ............. 383

Scientific Notes and News ........... 384

University and Educationat News ........ 387

Discussion and Correspondence:-

Headship and Organization of Clinicat Departments of First-class Medical Schools: Dr. ARTHur DEAN BevaN. Soil Nitrates: K. F. KeLlerman ............ 388

Scientific Books:-

Williston on the Water Reptiles of the Past and Present: Professor RICHARD S. LULL. Festschrift Max Bauer zum siebzigsten Geburstag gewidmet: DR. GEORGE F. KUnz. Gage on Optic Projection: DR. P. G. Nutring .................... 391

The Meteorology of Adelie Land, Antarctica: General A. W. Greely ............

Report of the Committee of the American Association of Anatomists on Premedical Work in Biology: Professor Henry McE. KNOWER .................... 397

Special Articles:-

Sex Determination and Sex Control in Guinea-pigs: DR. George PaPANICOLAOU ..

The American Association for the Advancement of Science:-

Section $C$ : Dr. JoHN JoHNSTON ..............

The Federation of American Societies for Experimental Biology; The American Society of Biological Chemists: Dr. P. A. SHAFrer.

MSS. intended for publication and books, etc., intended for review should be sent to Professor J. McKeen Cattell, Garrisonon-Hudson, N. Y.
THE FUNCTION AND TEST OF DEFINITION AND METHOD IN PSYCHOLOGY ${ }^{1}$

Amid all of the discussion current in the last few years among psychologists the unprejudiced outside observer might think that we were a body of men professing to develop and teach a science who did not know what that science was to deal with and without any idea or with too many ideas as to the methods that should be followed in undertaking to develop our knowledge of the unknown or undetermined subject-matter. Psychology is at once the science of mind, the science of consciousness, the science of experience, the science of behavior. Psychology must be studied only by careful watching of the processes of the individual, by the individual himself; one who does not proceed in this way is no psychologist, no matter how valuable his work may be as physiology or biology or sociology. On the other hand, we are assured by just as devoted and well-recognized psychologists that psychology must deal only with the responses of the individual, with what can be seen from the outside, and that what the first man deals with really has no existence, or at best is entirely irrelevant to the responses, to anything that is of scientific interest. If we are to be taken at our own valuation we are either altogether unfit to carry on the task we have set ourselves or entirely unprepared for it.

As a matter of fact I presume this comes from the youth of the science, at least from taking a definition and formal statements

1 Address of the Vice-president and Chairman of Section H-Anthropology and Psychology, Phila. delphia, December 30, 1914. 
of method too seriously. Other sciences have the same trouble with definitions. It would be as difficult to find a single phrase that would mark off physics from chemistry in an absolutely accurate and adequate way as to distinguish psychology from anthropology or human physiology, and quite as difficult to formulate a definition of either chemistry or physics that would satisfy every one, as to define psychology. From most traditional definitions, J. J. Thomson as physicist has no right to be discussing atoms, and similar violations of the sacred rights of physics as defined in the text-books might be cited on the part of men who are generally labeled as chemists. These men, and the better men in the sciences in general, are not interested in phrasing definitions but in solving the problems that their science, or closely related sciences present to them. On our side, much of the discussion, or the liveliness of the disciussion, comes from the fact that we assume that the definition must determine the science rather than the science the definition. It is assumed, tacitly, to be sure, that a definition is logically prior to the science, is a statement from which the science may be deduced or a program that the science is to follow in its development rather than a mere statement of what the science has done, or a formulation, as best we may, of the aims common to the mass of workers who are generally accepted as psychologists.

If we are to accept the view that a definition is the servant of our science rather than its master, if we are to say with Judd "that we all know what psychology is," then the test of a definition is that it shall state the aims of the science in the briefest form possible, and in terms that shall be best understood by the individuals for whom it is intended, that shall be least open to misunderstanding. If we consider the traditional definitions we find that each is open to certain objections when tested by these criteria. The traditional science of mind implies a general agreement as to what mind is, and this is lacking. It also suffers from the implication to men who do not know what psychology is that we are to deal with an entity of some sort, for all terms after they become familiar come to be regarded as denoting things. When mind is defined in a way to avoid this implication, as it usually is in the succeeding sentence, it is no longer recognizable by the uninstructed. The same objections hold against consciousness; it was at first innocent enough of mystical significance, but a very few years of use to designate the material to be studied set it up as a thing or inner force. Hypostatization followed close upon the heels of its entrance into definitions. If psychologists were to study it as the material of their science it must be the equivalent of mind as mind is of soul, it must then be an active agent that psychologists can see, although, like the holy grail, sight of it is granted only to the pure in heart. Experience as a substitute for consciousness or mind escapes some of the disadvantages in that it is less likely to be personified or substantialized, but it is difficult accurately to separate the part of experience that psychology is to treat from that touched upon by the other sciences. When this is accomplished it affords little advantage over mind or consciousness.

In view of all these circumstances a change from the inside to the outside, to describe the object of psychology as behavior, offers the most advantages. Behavior is at once simple enough to require the minimum of definition and is hardly capable of being transformed in meaning to designate a thing or force. It takes, too, the attitude toward the mental of the average non-reflective individual. The ordinary 
man is interested primarily in the mind of others rather than in his own. He is interested in furnishing stimuli of various sorts to other men that shall lead or compel them to act in certain ways rather than in how he himself or his fellow feels as he acts. The advertiser is content if his copy induces men to buy, the orator if his discourse brings him votes or changes the mind of his audience to his own opinion. The salesman is content with his knowledge of practical psychology if his patter leads the buyer to part with his money, the general or statesman if he can divine how his opponent is likely to act under the conditions he presents to him. In the simplest as in the most complex and important affairs of life the practical man is concerned not with mental states, but with behavior. He usually assumes mental states to account for behavior, but they are purely hypothetical, not the result of introspection, however crude. Good temper and bad temper, conceit and modesty, weak will and strong will, are all names for qualities that can be recognized through behavior alone, or at least can be no more easily recognized through introspection than by observation. The bad-tempered man is as little aware of it and can give as little explanation for it as his friends or enemies. He knows of his weakness only by observation of his actions rather than by any mental process that precedes or accompanies his acts, and is probably, through his prejudices, even less likely to recognize the quality than are others. To turn in upon one's self, to have "too much contemplation in one's eye," is for the average man a sign of weakness, a forerunner of mental disintegration. The mental states of the uninitiated are not known through watching himself, but assumed to explain the behavior of another man.

On the theoretical side, behavior has the advantage over the more subjective terms as a designation of the subject-matter of psychology that it includes many processes that are treated by practically all of us. Very much of the active life bears very little ascertainable relation to consciousness when closely analyzed. It is not putting the matter too strongly to say that the more the voluntary processes are analyzed, the smaller part does consciousness seem to play in them. The less voluntary processes, habit, instinct and the various impulses are also included in the list of psychological processes, although little or no consciousness accompanies them. They are quite as easily predicted from without as from within. Even the learning processes and the recognition processes are studied quite as easily by observation as by introspection. One knows that one recognizes through observation of his mental states, but sees very little of how he recognizes. One can be almost as sure that another has recognized him as he can that he has recognized the other. Neither can determine immediately how the recognition has taken place. Thinking by the most recent workers would be put on much the same level. Even the self or personality, if one is to use the more familiar and objective term is quite as much removed from introspection as from observation. On the whole, if one were compelled to choose between behavior and consciousness as a designation of the subject-matter of psychology and then should apply the term in all logical strictness, it would be found that more of the actual content of the average text-book on human psychology would need to be eliminated if one deleted the portions that applied to consciousness than if one omitted those sections that were devoted to behavior.

If we leave human psychology and turn to animal psychology, no one would deny 
that a study of behavior is all that we have aside from an uncertain amount of discussion as to how closely or remotely the human mind can find a parallel behind the actions of the lower forms. Similar is the problem raised by the assertions of the recently prominent group of philosophers who insist that consciousness is non-existent-at the most an illusion. For them psychology as the science of consciousness has ceased to exist. While fashions in philosophy change too often for the psychologist to attempt to square his definitions with all of them, it is nevertheless interesting to see that psychology defined as behavior is quite as applicable to the philosopher without a mind as to the rest of intelligent creation. His responses to stimulation, his perceptions as they modify his actions, his memory and eapacity for reasoning with varying degrees of accuracy under different conditions, even the conditions that led to his denying that he was conscious, could be studied with some degree of satisfaction. Antecedent acts and experience could be shown to give rise to the various actions, and would go far toward explaining them.

But it does not follow that because much of the material in the text-books and much that the common mind regards as mental is really a matter of behavior that a definition of psychology as the science of behavior would change the nature of the science. As was asserted in the beginning, the science makes the definition, not definition the science. There is no mental process, however strictly one may follow the subjectivist, that does not have some influence upon behavior. The very description of them in words itself implies behavior. Perception in all forms, images of all types, feelings and emotions, not to mention the mental antecedents of voluntary action, all play a part in determining the character of the individual. Each modifies his be- havior. If one understood thoroughly the behavior of any man he would also understand his consciousness. It is possible to neglect behavior in the study of consciousness, but not to neglect consciousness in the study of behavior. The only ones who could object to the statement that behavior was to be understood in terms of consciousness are the men who deny the existence of consciousness, and they need no convincing as to the possibility or even the desirability of defining psychology as the science of behavior. To my mind, the adoption of behavior to designate the subject-matter of psychology need not change in the least the treatment of the subject as ordinarily presented. Even the individual who finds no interest in anything but the classification of his own mental states, if such there be, could go on with his classification, and, if he classified all of his states, would find an awareness of his own movements among them, and find these very important both as the beginning and the end of his series. He would probably prefer another description, but his own work would be included in the definition, he would still be within the pale. By adopting the definition we change our description of the science not the science itself.

It should be added that in the nature of the case no definition can be satisfactory. No single phrase, or paragraph even, is sufficient to definitely delimit the subjectmatter of psychology. Even a short text can not include and describe all that might be and is in reality included in the science. The meanings of terms are bound to grow, and with each change a definition becomes inaccurate. Of course, were one to take the other attitude that the definition fixes the science, the difficulty would be avoided. But there is no absolute authority to fix that definition and even if it could be fixed by such an authority the science would soon 
find itself on a procrustean bed. Advance would be impossible. If the seience is to determine the definition, the statement can be at best a short-hand description of it, it can do no more than approximate either completeness or accuracy. A definition is no more than a choice of evils. All that is incumbent upon us is that of all evils we choose the least.

Even more the subject of conflict at the present moment than the definition of the science is the question of the methods that may be employed in developing it. On this point psychologists have been even more divided and each more strenuous in insisting upon his own attitudes. Whether a new science attracts the more aggressive and in consequence more intolerant men in the scientifie community, or the very uncertainty of the subject of method leads to an over-emphasis of assurance, a whistling to keep up courage, or what the psychoanalyst would call an emotion that arises from the constant repression of a complex of doubt that must be kept below the threshold because of its unpleasantness, it is undoubtedly true that psychologists have spent more time than most scientists in insisting upon their own method or the methods that they have adopted. Ex cathedra statements, and assertions that all who do not follow their own method are not psychologists and that all who do follow it and reach results that do not conform with their own are not psychologists, have been relatively very frequent. Several instances may be mentioned. Wundt, as you all know, early in the history of the science asserted that no man who could not obtain the sensory and motor differences in reaction times was to be included among psychologists, and only recently after a controversy with Bühler on the Ausfrage method he announced that he would read no more reports on work done by that method. At present Müller and Meumann, both respected leaders in the science, are indulging in a controversy in which each seems to fall back upon similar personal criteria as a justification for their impatience with the standpoint of the other. No psychology without introspection has been a motto frequently implied if not explicitly asserted, and, ironically enough, an advocate of the newest method to claim a monopoly turns upon the former tyrant among methods with the assertion that it has been dealing with an illusory material, that the method is worthless, and that its followers have retarded the development of the science and are in general cumberers: of the earth. Turn about is fair play, but: to meet intolerance with intolerance is; usually more interesting and picturesque than helpful to the science.

To my mind the great difficulty on both sides lies in the same tendency that makes trouble with the definition, the method rather than the science is given priority. The method should be the servant of the science, not the science the slave of the method. The only test of a method is its accomplishment. Just as with definition no authority exists that can once and for all say this is the method, follow it or cease to be a psychologist. Attempts on the part of any one to take that tack are quite cer. tain to be a means of covering the uncer. tainties or the mistakes of the author; they are certain not to be fruitful for the science. These must have their origin in prejudice rather than in any universal law revealed to that individual alone. Any method that gives results must be kept, and the more we have the better. What are to be called results offers room for difference of opinion, but the gradually devel. oped judgment of the recognized members of the science and of related sciences will be the final arbiter of that question. With 
the complexity of our subject-matter any method that can give a point of attack is to be encouraged on general principles. The methods that prove fruitless will disappear soon, the valuable ones will assert themselves. Meanwhile a broad hospitality that will encourage originality, rather than a hidebound insistence upon any single method, will certainly be beneficial for the advancement of the science.

That the advocates of a method are prone to exalt the method at the expense of the science, to make over the science if not the man to conform to the needs of their method, can be seen to-day in the writings of both introspectionists and behaviorists. The introspectionists in general desire to put all the essential mental operations on the inside, to find them in images, while Watson, their newest and most vigorous opponent, would put all on the outside. Thus in the thought processes the more thoroughgoing believers in images insist that thinking that does not go on in images is not thinking, or that the individuals who announce that they do not use images have overlooked their images through faulty observation of some sort. They themselves heap up images for each of the reasoning operations, in spite of the fact that many of the processes they mention are obviously individual if not irrelevant to the end that is accomplished. Watson, similarly, after announcing that psychology is a branch of behaviorism and its method is the observation of external responses under experimental conditions, feels himself compelled to transfer the thinking process in its entirety to the outside where the experimenter can discover all that goes on. Thinking must be found in contractions of the larynx, in slight movements of the larynx, or in other movements at present undiscovered which must however lie upon the surface of the body. It is not apparent why he should insist on the slight movements of the larynx, for which delicate apparatus should be used, rather than upon the full movements of speech which may be even more completely analyzed by the ear. If the language of the individual does not tell us why he reaches certain conclusions when he thinks aloud, I can not see how the slight movements made when he thinks to himself are to be of any greater aid. So far as any evidence on the subject exists, the movements in thinking are but faint replicas of the movements of ordinary speech.

If we take the thinking process as an instance, I am inclined to believe that the great difficulty is not so much with the method as with the way in which it is ap. plied. Advocates of both tend to deal too much with irrelevant materials. As an impartial onlooker I am convinced that much of the imagery that we hear so much of in the long introspective accounts is wholly or largely irrelevant to the problems, and I am sure if I may indulge for a moment in the cocksureness that I am criticizing, that the slight recorded movements that are mentioned on the other side would be at most irrelevant accompaniments, rather than essential conditions of the thought process. If one observe any bit of thinking as revealed in the speech of another or in one's own consciousness, if one happen to have a consciousness, it is seen that there is no difficulty in knowing that a conclusion has been reached and in deciding that it is or is not adequate. How the conclusion is reached, and why it seems adequate or inadequate, is revealed neither to introspection nor to observation. To answer either of these questions one must proceed as one would in the natural sciences by varying the antecedents of each process until one discovers that certain are the real causes and others are chance accompaniments. If experimentation is not 
possible, study of the conditions under which the conclusions are reached and of the way the conclusion varies with the immediately preceding events and with earlier experience may give the same result. Heaping up descriptions of accompanying imagery or of accompanying movements may be of no more value to this end than is collecting postage stamps in the study of the causes of events in the world's history. Both may be interesting as mementoes, but throw no light upon underlying causes.

In the list of irrelevancies in connection with the reasoning processes is the question whether one may think without images so much under discussion at the present. Proof that men may think without images is a valuable advance, not in itself, but in so far as it raises the question how he really does think. If two men reach the same conclusion, one with, the other without images, obviously the presence or absence of imagery is equally unessential. The only alternative is to believe that the one man has images, but does not notice them, or that the other thinks in spite of his images. That one thinks and how is the essential, and the individual with the imagery is no more and no less effective in attaining conclusions than the one without. They are equally accurate, and neither knows directly how he accomplishes his results. The quarrel over the nature of the mental state has obscured the more important problems of reasoning. For this reason it seems to me that the important accomplishment of the Würzburg school has been not to prove that thinking may go on without images, although I am prepared to accept that, too, but to show that the antecedent purpose, the Aufgabe, determines the course of thought. One shows what is not needed, the other an element that is essential.
From this standpoint the attempt to set up a new element of pure thought rather than to study the actual operations of thinking is unfortunate. All that has been shown by introspection is that images are lacking, not that anything else is present. To assume pure thought is to hypostatize our ignorance. Particularly objectionable is this because no attempts have been made to determine its conditions, to set limits to it, or to reduce it to any law. It is merely another addition to our collection of postage stamps, perhaps even less valuable than the others because denomination and name of the country have been worn off, and no one knows what the remnants of the portrait mean. The great disadvantage with the introduction of the term, is that, as with all names, in the course of a few years all problems of thought, all reasoning operations, will be explained by reference to it. If one asks why John reasons better than Jane the answer will be that John possesses more of the pure thought element. To be sure, none of the advocates of the new school mean anything of the kind at present, and it may never develop in this way, but the tendency to use these more or less mystic entities in mystic ways is strong. A word becomes a thing on the slightest provocation.

By asserting that conscious states may be irrelevant, it is not implied that they are always or even usually irrelevant; in fact, in opposition to Watson it seems to me that many mental states are relevant and that one knows what goes on in mind quite as well or better from the inside than from the outside. Not only does the study of imagery indicate its existence in all but relatively few individuals, but Meumann's and many other studies indicate that it has an important influence upon the method and capacity of an individual's learning, his spelling, the methods of mental calculation and many other activities. To take 
a concrete instance, if I may be indulged for a mention of names: Here are Yerkes and Watson who have been working approximately the same time with the same problems and materials and attaining the same conclusions in their chosen field. But recently, when they came to the application of methods to human psychology, one makes much of imagery and of introspection in general, as much as the most ardent introspectionist could wish, while the other denies the existence of imagery except for the sake of argument in a few sporadic cases. If one assume the attitude of the average man and argue from behavior to consciousness, it is evident that while Yerkes has a large amount of concrete imagery, probably dominantly visual, Watson has relatively little concrete imagery, and what he has is of the motor type. An assumption of this sort on the basis of behavior alone, if we are to include writing psychological treatises under behavior, is of course not to be compared in value with a few minutes' introspection, but may be ventured as a guess. If this holds, not only is consciousness and even imagery an essential determinant of behavior, but it is possible to show that one important bit of the behavior of the man who would most emphatically deny the existence of imagery is due to imagery or its lack. To ascertain that one does not have imagery is just as much a contribution of introspection as to determine that it exists. To give over introspection altogether is to abandon the method that has given much if not most of the body of knowledge that we have at present and to insist that we use only a method that so far has been little tried, and which, in the form that is suggested, the inference of mental states from slight movements, has when tested proved relatively futile.

If one broaden slightly the term con- sciousness and the implication of introspection it seems possible to put the problem of psychology in a form that removes all ground for complaint on all sides. This is to include in consciousness and among ideas the fundamental states upon which all effective mental life depends. More immediate than the image, more certainly made out than any slight movement, is the series of assurances that we have that certain events, subjective or objective, take place. We know that we recall, we are sure that we recognize, believe, see objects, that we are pleased, desire certain things, and are on the point of striving for them. These assurances are common to the man who has images and to the man who has none, to the man who believes that mental life is fundamentally sensory and to him who regards it as altogether motor, to the realist and to the idealist. They might be called mental states, or mental functions, had not both been spoiled by use. It is the mind of the practical man before he does any theorizing. It is likewise the starting point of the psychologist. $\mathrm{He}$ begins to deal with images and with slight movements only when he becomes sophisticated, and when he becomes sophisticated he forgets his starting point and substitutes his explanation of consciousness in terms of images, movements, or pure thought for the fundamental reality. In time he assumes that the explanation instead of the fact is the reality, just as the naïve man assumes that memory, attention, will and self are immediately known realities.

My plea is that the real subject-matter of psychology is the fact that we attain conclusions, that we perceive distance, that we are prepared to act, rather than the imagery, or the movements that accompany, precede or succeed. This group of facts common to all schools may be explained in different ways or need not be explained at 
all. It is always possible to determine the laws of any mental operation, as has been done by the experiments on memory, by the statistical method applied to everything from heredity to advertising by the Cattell school and others, by the investigators in education, in medicine, in the studies in efficiency, and also in the early experiments on Weber's law and reaction times. Whether classed as conscious processes or as behavior, every one is capable of deciding whether a sound is more intense than the preceding, whether a picture is more or less beautiful than another, of recalling and recording the words that were spoken in a conversation a month ago (whether truly or not is for the experimenter to decide) of pressing a key when a stimulus is given. That is all that these experiments require. How these processes are carried out is entirely indifferent. Granting that they may be carried out, a science of psychology is possible. All disagreement between schools is as to how these judgments are made, that they are made all agree.

This conclusion does not mean that psychology need stop here. How one remembers, the mental antecedents of an act and all questions of classification and of ultimate explanation are bound to be raised and are at once valuable and interestingmy only contention is that the nature of the explanation offered makes no difference to the fact to be explained, a statement that is obvious enough but which seems to be lost sight of in much of the controversy that is raging. The laws that I have been mentioning correspond to the simple physical laws of the lever, of gravitation, Ohm's law and Joule's law, etc., while the controversy rages about questions related to the physicist's discussion of the nature of ether and the atom and the so-called law of relativity. Whether one is to use intro- spection or observation as the method of psychology arises only when one seeks an explanation of mental laws, not while discovering them. For this explanation introspection, observation and speculation on the basis of both and of knowledge obtained from all related fields can, I believe, all be used to advantage. No one method is complete in itself; in most experiments all three are used, no matter to what school the investigator belongs.

One may take as an instance such an experiment as those of Ach on action with the reaction time method. The fundamental result, let us say, is to determine that the response that follows, showing two numbers written one over the other, depends for its character and the time required upon the purpose. That fact is independent of the method used. If one is interested in the antecedents of the movement in consciousness, one must introspect. But raw products of introspection are valueless. One must be assured that the images are essential by repetition of the introspection with the same individual and other individuals under varying conditions. To determine the nature of the purpose and the way it acts one may see if it has any conscious form, and may indulge in physiological speculations, may look for analogies in physiological laws, or one may observe the bodily attitude, the set of the muscles before and during the response. The final acceptance of any explanation will be found to depend upon a harmony of all these observations with each other and with related facts. In any case, the determination of the laws is related to their explanation as observed fact is related to theory in physics or physiology.

The question might well be raised whether the certainty of recognition, of decision and the other processes we have mentioned as eonstituting the primary facts of 
the mental life, are the products of introspection or observation. On this point there is room for difference of opinion. A large number of the processes, recognition, judgment, feeling, seem to be more closely related to introspection; the active processes, on the other hand, the comparison of divided with accumulated repetitions and perceptions, are either derived from observation or a combination of observation and introspection. In addition to these immediately observed, generally recognized mental states and functions there are immediate facts derived both by introspection and by observation aided by experiment. Such are on the one side the awareness of the different sorts of imagery, the course of association, colored hearing and the different synesthesias, and, on the other, the changes in circulation with mental operations, the slight movements, and the larger movements of expression. These and many other immediate facts of consciousness escape the untrained observer or introspector, but are needed to round out the series of mental facts and to aid in the formulation of expansions of other facts and laws.

In brief then there is room in psychology for the greatest variety of standpoints and for all methods, provided only the spirit of live and let live prevails. The science is above the individual and the individual's preference in definition and method. The definition and method in turn must grow out of the science; they are not given once and for all, and the science forced into them. Given a set of facts and laws of fairly general acceptance, the form of statement again is largely a matter of individual preference guided and tested by the interest and comprehension of the group for whom the discussion is intended. As in most sciences a mixture of explanation and theory with bare fact may be used, or bare facts may be stated and explanation follow or be omitted. Methods that are assumed by the investigators may be with advantage followed in the restatement of their results. But formulation of results and their presentation in a treatise can no more be determined by a priori principles than can the statement of definitions or the prescription of methods. In brief, my plea is for the widest liberty in all respects with a testing of everything by results rather than by formulæ or even by tradition. In the light of the tests so far available it seems to me that defining psychology as the science of behavior and the use of all methods possible under suitable precautions will lead soonest to the end of psychology, the discovery of mental laws and their explanation.

And we have no reason to be ashamed of the progress of the science. More has been done in the discovery of fundamental laws in the last sixty years than in all the preceding centuries from Thales to Fechner, and interesting problems open to our methods of approach on every hand. These laws, the immediate results of experiment, are not in dispute. They have stood the test of repeated investigation, and are accepted on all sides. There is much more difference of opinion about theories, but even here we have made progress. Except for the fact that we still take our theories very seriously, even our theories offer no more occasion for controversy than do theories on similar problems among physiologists, or zoologists or much more than between physicists and chemists.

\section{W. B. Pillsbury}

\section{MRS. HENRY DRAPER}

Anna Palmer Draper, widow of Dr. Henry Draper, died on December 8, 1914, at her home in New York City. Her name will always be honorably associated with the science of astro- 